Central European Journal of Energetic Materials, 2016, 13(2), 427-443

ISSN 1733-7178

e-ISSN 2353-1843

\title{
The Relationship between Impact Sensitivity of Nitroaromatic Energetic Compounds and their Electrostatic Sensitivity
}

\author{
Narges ZOHARI ${ }^{1 *}$, Seyed Abolfazl SEYED-SADJADI ${ }^{2}$, \\ Sadegh MARASHI-MANESH ${ }^{2}$ \\ ${ }^{1}$ Faculty of Chemistry and Chemical Engineering, \\ Malek-ashtar University of Technology, \\ P.O. Box 15875-1774, Tehran, Islamic Republic of Iran \\ ${ }^{2}$ Faculty of Chemistry, Iran University of Science and Technology, \\ P.O. Box 16846-13114, Tehran, Islamic Republic of Iran \\ "E-mail: nargeszohari@gmail.com
}

\begin{abstract}
This study presents a linear relationship between the impact sensitivity of nitroaromatic energetic compounds and their electric spark sensitivity. The methodology assumes that the impact sensitivity of a nitroaromatic energetic compound with the general formula $\mathrm{C}_{\mathrm{a}} \mathrm{H}_{\mathrm{b}} \mathrm{N}_{\mathrm{c}} \mathrm{O}_{\mathrm{d}}$ can be expressed as a function of the electrostatic sensitivity, the number of $\mathrm{NH}_{2}$ group substitutions in the 2,4,6-trinitrophenyl ring and non-additive structural parameters. The root mean square and absolute standard deviation of a newly introduced correlation were respectively found to be 2.4 and 2.0 for 27 nitroaromatic energetic compounds. The proposed new correlation was also tested for 7 additional nitroaromatic energetic compounds, which have complex molecular structures such as 1-(2,4,6-trinitrophenyl)-5,7-dinitrobenzotriazole and 1,3,7,9-tetranitrophenoxazine.
\end{abstract}

Keywords: energetic materials, nitroaromatic compounds, impact sensitivity, electrostatic sensitivity, safety

\section{Introduction}

Impact, electric spark, shock, heat and friction are several important stimuli in the initiation of energetic compounds $[1,2]$. The degree of sensitivity of an 
energetic compound to electrostatic discharge is known as the electric spark sensitivity, which can be determined experimentally by exposing the compound to a high-voltage discharge from a capacitor. The impact sensitivity of an energetic compound is measured by subjecting a sample to impact in a standardized drop weight machine in which the weight is dropped from various heights and evidence of reaction or no reaction is recorded.

Recent trends in novel energetic materials research has focused on reducing their sensitivity to accidental initiation by shock, impact, electric spark stimulus and so on. Reliable estimation of sensitivity parameters of explosives is of utmost importance before their actual synthesis. Several theoretical or empirical methods have been introduced for the estimation of the various sensitivity parameters of nitroaromatic energetic compounds [3-16].

\section{Theory}

The sensitivity of an energetic compound is a consequence of the kinetics and thermodynamics of its thermal decomposition. So there is no unique model of the initiation mechanism of energetic materials by electric spark [15]. The primary dissociation reactions can be supposed to be identical with the primary splitting processes of low-temperature thermolysis and detonation transformation of molecules of these materials [16]. The electric spark sensitivity of energetic compounds is affected by various parameters, such as the chemical nature of the compound [9], its particle shape and size [10, 11], the temperature [12], the moisture content [10], its thermal and impact reactivity [10, 13-15], the configuration of the electrodes, and the general structure of the circuit and the discharge time [10]. Although there are various effects that influence the electrostatic sensitivity of energetic compounds, a linear relationship between the test results obtained with various apparatuses can be found [16]. Zeman et al. [17] reported that the mechanisms of spark energy transfer into the reaction center of the molecule were different in measurements using two different instruments (RDAD and ESZ KTTV).

Because of the differences between operators, type of apparatus and ways of conducting experiments, the results obtained for the impact sensitivity of energetic materials vary from laboratory to laboratory [18].

There are several reports concerning investigations of the relationship between impact sensitivity and molecular structure [19, 20], bond dissociation energies [21], surface electrostatic potentials [22], friction sensitivity [23], molecular electronegativities [24, 25], activation energy of thermal decomposition 
[26], heats of fusion [27] and particle size of energetic materials [28]. Kočí and co-workers investigated the relationship between the electrostatic sensitivity of some poly nitro compounds and their impact sensitivity [15].

The main purpose of this article is to report an investigation of the correlation of impact sensitivity of nitro aromatic energetic compounds with their electric spark sensitivity about which there have been few previous reports. We inclined to the view that the sensitivity of energetic materials is primarily due to the chemical nature of these materials. So a better understanding of the relationship between these parameters should provides a framework for the design or development of novel energetic compounds with low sensitivity and high performance.

\section{Materials and Methods}

Table 1 shows experimental data for the electrostatic sensitivity and impact sensitivity of several nitroaromatic compounds. The electrostatic sensitivity of energetic materials is defined as the sensitivity to electrical discharge produced by discharging a high voltage capacitor through a needle inserted into the sample. The amount of energy discharged can be varied. Because the electric spark sensitivity depends on both the electrode configuration and circuit structure, we can expect different results in different studies.

The experimental data of the electrostatic sensitivity of nitroaromatic energetic compounds collected together in Tables 1 and $3[7,15]$ were obtained using a RDAD instrument. In this method the capacitors were set to allow measurements in the voltage interval from 8 to $14 \mathrm{kV}$. If initiation occurred, the next measurement was made with a voltage lowered by $0.2 \mathrm{kV}$. If initiation did not occur, the voltage was increased by the same value. The electrode has a steel base bottom. The sample container is a piece of flexible tubing of $5 \mathrm{~mm}$ height and $5 \mathrm{~mm}$ diameter [17].

Experimental impact sensitivity data is obtained using a drop weight impact test. The sample is subjected to impact by a standard mass falling from different heights. Evidence of reaction or no reaction is reported. Usually, a sample is tested using a $2.5 \mathrm{~kg}$ hammer, but other weights can be used. The different test procedures for measuring impact sensitivity define positive results in different ways. Some tests describe positive impact sensitivity by the first reaction and some of them describe the height for which there is a $50 \%$ probability of an explosion. So the results obtained using different methods might give different values. In addition, these results are highly dependent on the experimental conditions and methods. It will be shown in this paper that the values of impact 
sensitivity calculated using our new proposed correlation have better consistency with the experimental data obtained by the first reaction.

\section{Results and Discussion}

In spite of the various parameters that influence the experimental sensitivity values, our study has shown that it is possible to correlate the impact sensitivity data of nitro aromatic compounds with their electric spark sensitivity (see Table 1). Analysis of the relationship between impact sensitivity and electrostatic sensitivity results in a linear equation (Equation 1). In this equation, the impact sensitivity is only a linear function of the electrostatic sensitivity, the number of $\mathrm{NH}_{2}$ groups, and non-additive structural parameters. The following equation was derived using the multiple linear regression method [29] on the basis of the data presented in Table 1:

$$
E_{I S}=2.572+0.942 E_{E S}+34.175 F_{n-N H_{2}}+17.105 F_{I S}^{+}-8.272 F_{I S}^{-}
$$

where $E_{I S}$ is the impact sensitivity in $\mathrm{J}, F_{n-N H_{2}}$ is the number of $\mathrm{NH}_{2}$ group substituted into the 2,4,6-trinitrophenyl (TNP) ring, $E_{E S}$ is the electrostatic sensitivity in $\mathrm{J}$, and $F_{I S}^{+}$and $F_{I S}^{-}$are the increasing and decreasing contribution of non-additive structural parameters, respectively. A value of 0.99 was obtained for $\mathrm{R}^{2}$ (the coefficient of determination) for Equation 1 .

\section{Definition of $F_{I S}^{+}$and $F_{I S}^{-}$}

For nitro aromatic compounds $F_{I S}^{+}$and $F_{I S}^{-}$can be determined according to the following conditions:

a) For the nitro aromatic energetic compounds with general formula TNP-( $\left.\mathrm{NH}_{2}\right)$ n, the $F_{n-\mathrm{NH}_{2}}$ is $0.75,2$ or 3 for $n N H_{2}=1,2$ or 3 positions in the molecule, respectively.

b) For molecules which have 2,4,6-trinitrophenyl (TNP) in the form TNP-X, the value of $F_{I S}^{+}$is 1.0 for $\mathrm{X}=-\mathrm{R}$ or $-\mathrm{OR}$. If there is the moiety such as ${ }^{\mathrm{N}} \mathrm{Y}^{\mathrm{N}}$ in the molecule, the value of $F_{I S}^{+}$is 0.25 .

c) If the nitro aromatic molecule has the general formula TNP-X-TNP, the value of $F_{I S}^{-}$is 1.0 for $\mathrm{X}=\mathrm{SO}_{2}$, TNP or $\|^{N}-\mathrm{C}-\mathrm{C}-\mathrm{NH}$. If $\mathrm{X}$ is $\mathrm{CH}=\mathrm{CH}$ or two TNP attached directly together, the value of $F_{I S}^{-}$is 0.5 .

According to Table 1, the root mean square (rms) and the average absolute 
deviation are 2.4 and $2.0 \mathrm{~J}$, respectively. Moreover, the estimated impact sensitivity using our new correlation is more than $3.5 \mathrm{~J}$ for the reported values for only five energetic compounds. Table 2 shows the statistical parameters for the variables in Equation 1. In Table 2, the variable coefficients show the effect of them in the model. The standard error shows the precision for estimations of coefficients which can be determined with several measurements. The P-value can be used to assess the significance of an observed effect. The accepted P-value for variables that are significant is less than 0.05. According to the statistical parameters and $\mathrm{R}^{2}=0.99$, our new predicted model is in good agreement with experimental results. The new equation was tested for 7 other nitroaromatic energetic materials, the results being presented in Table 3. These results also have a good relationship with the new model, thus confirming the new method.

As we expected, the coefficient of $E_{E S}$ in Equation 1 has a positive sign, which confirms that higher values of these parameters can increase the values of $E_{I S}$. Also it was shown that the presence of amino group substitutions in the TNP ring can enhance the thermal stability and reduce the impact sensitivity $[12,30]$. Thus TATB is very insensitive to impact stimuli [31]. The predicted impact sensitivity for amino derivatives of 2,4,6-trinitrophenyl, e.g., PAM, DATB, and TATB, by the new proposed correlation is consistent with experimental data. However, the results predicted using Equation 1 have confirmed that increasing the number of amino substitution groups in the TNP ring has an important contribution in predicting their impact and electrostatic sensitivities as well as their thermal stability parameters $[12,30,31]$. Kočí et.al. reported several relationships between the electrostatic sensitivity of some poly nitro compounds and their impact sensitivity [15]. So the energetic materials studied by them can be classified into several groups.

Figure 1 shows the relationship between the predicted impact sensitivity values and the experimental data for nitroaromatics which were presented in Tables 1 and 3. Although this new proposed correlation has good characteristics, it can only be used for nitroaromatic energetic compounds with general formula $\mathrm{C}_{\mathrm{a}} \mathrm{H}_{\mathrm{b}} \mathrm{N}_{\mathrm{c}} \mathrm{O}_{\mathrm{d}}$. 


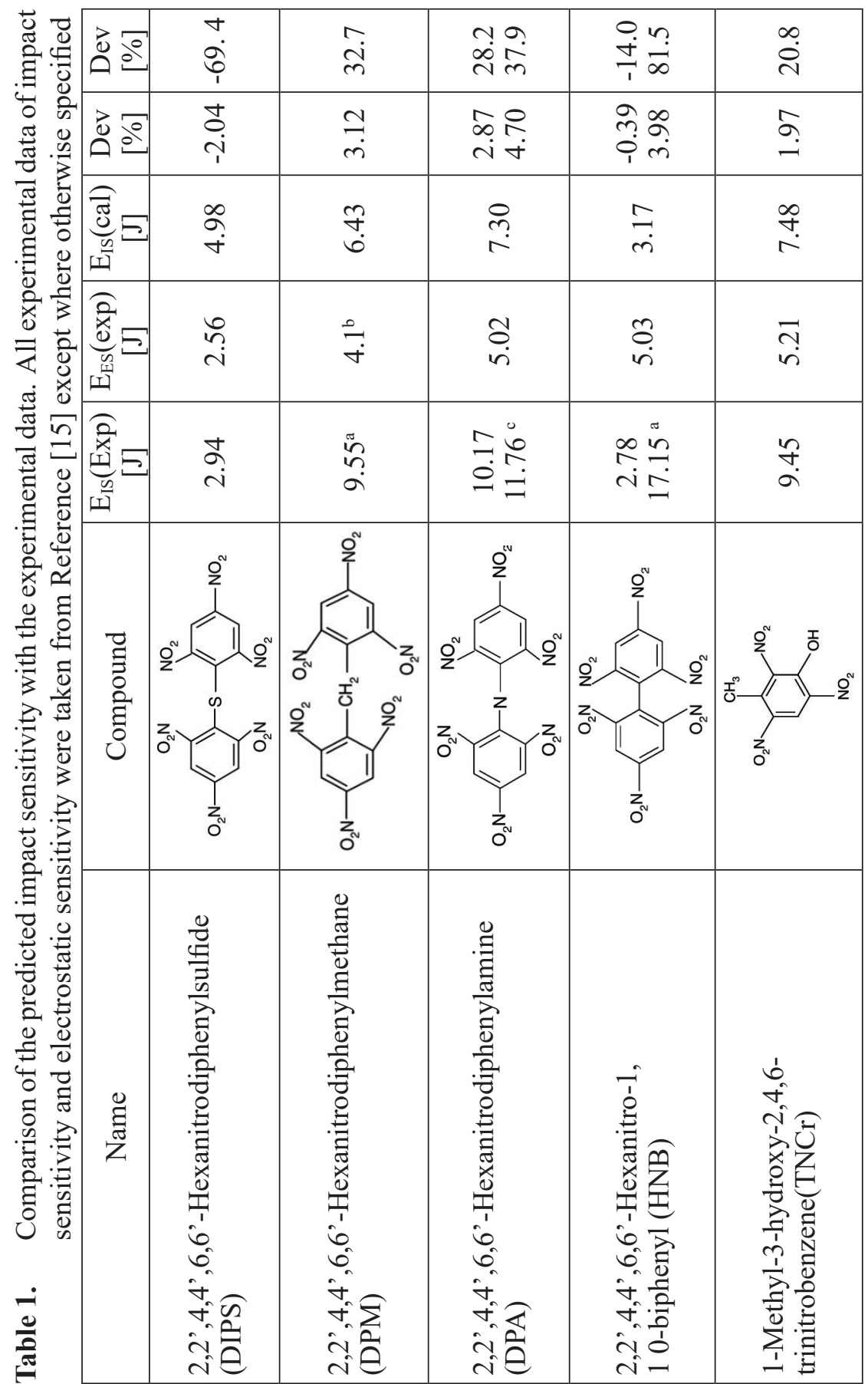


The Relationship between Impact Sensitivity of Nitroaromatic Energetic...

\begin{tabular}{|c|c|c|c|c|c|}
\hline ฉ̊ & N & ஸे & $\frac{\infty}{1}$ & $\begin{array}{l}0.0 \\
\underset{i}{ \pm}\end{array}$ & $\begin{array}{l}\vec{b} \\
\dot{n}\end{array}$ \\
\hline อ̊ & $\frac{a}{0}$ & ஸे & n? & 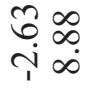 & ஜֶ \\
\hline 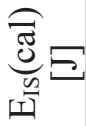 & $\begin{array}{l}\stackrel{n}{\ddagger} \\
\stackrel{n}{m}\end{array}$ & $\frac{⿱}{N}$ & $\begin{array}{l}\text { ऽ̦ } \\
\infty\end{array}$ & $\stackrel{n}{n}$ & $\frac{\pi}{\pi}$ \\
\hline 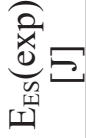 & $\begin{array}{l}\text { กै } \\
\text { nิ }\end{array}$ & $\begin{array}{l}\dot{a} \\
\stackrel{\partial}{\dot{r}}\end{array}$ & $\stackrel{\infty}{\stackrel{\infty}{\sim}}$ & ๘ँ & $\tilde{n}$ \\
\hline 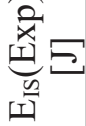 & $\begin{array}{l}\nabla \\
\dot{\sigma}\end{array}$ & $\begin{array}{l}0 \\
\infty\end{array}$ & $\ddot{7}$ & 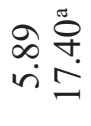 & $\begin{array}{l}\vec{\sigma} \cdot \\
\text { ๙े }\end{array}$ \\
\hline 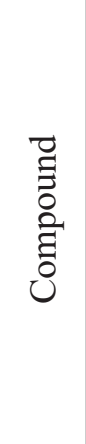 & $z^{N}$ & & & & \\
\hline 急 & 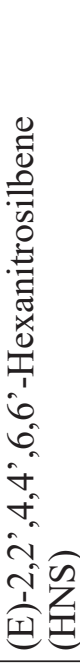 & 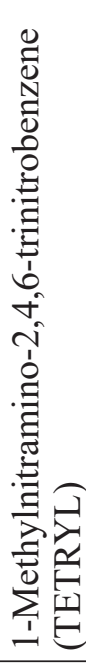 & 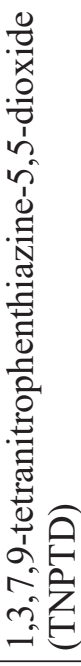 & 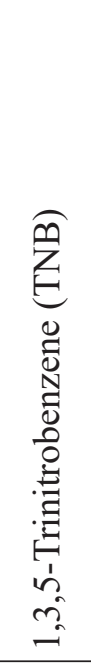 & 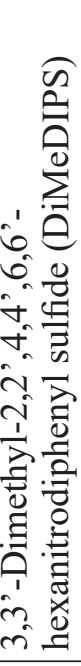 \\
\hline
\end{tabular}




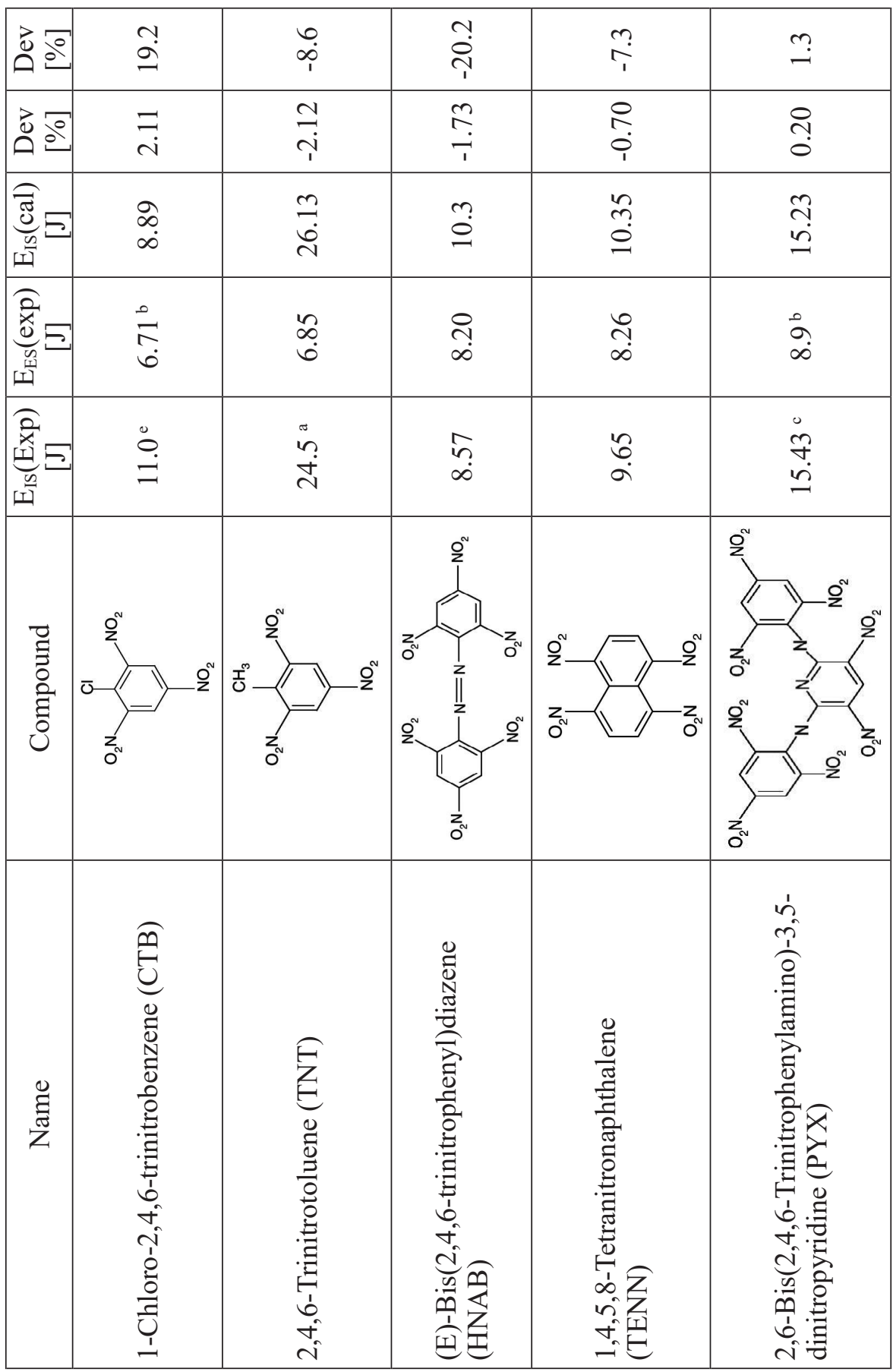




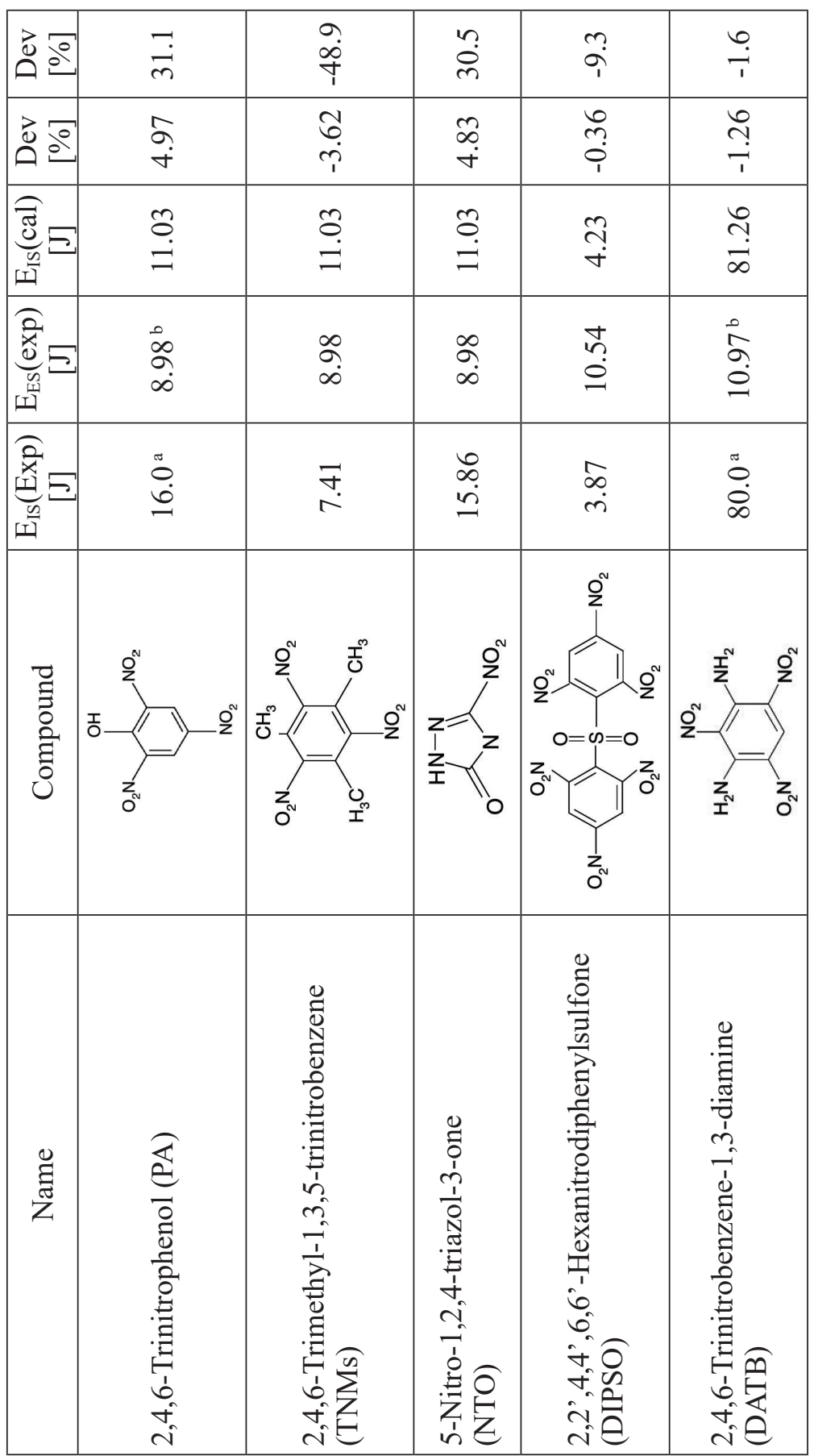




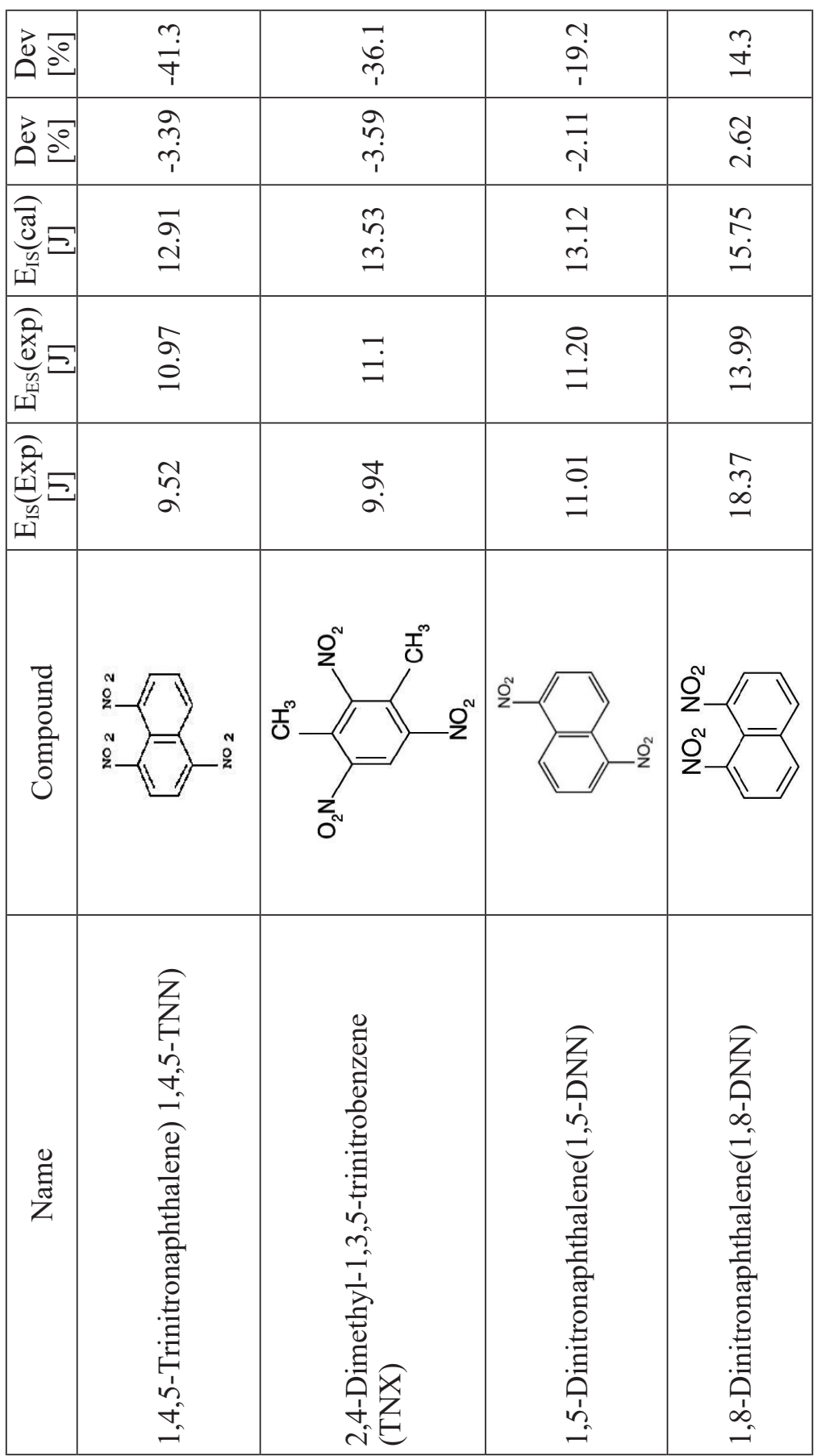




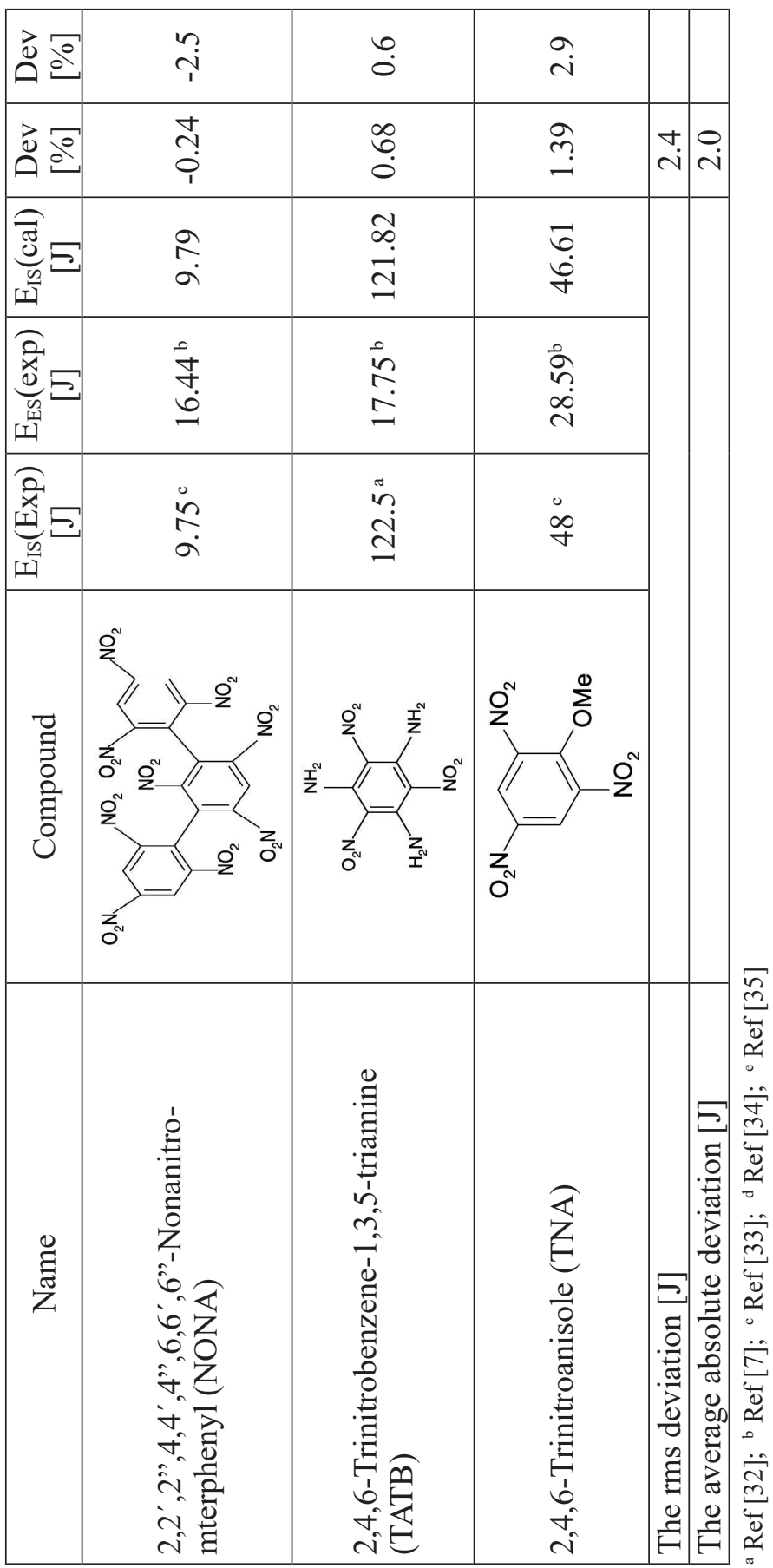




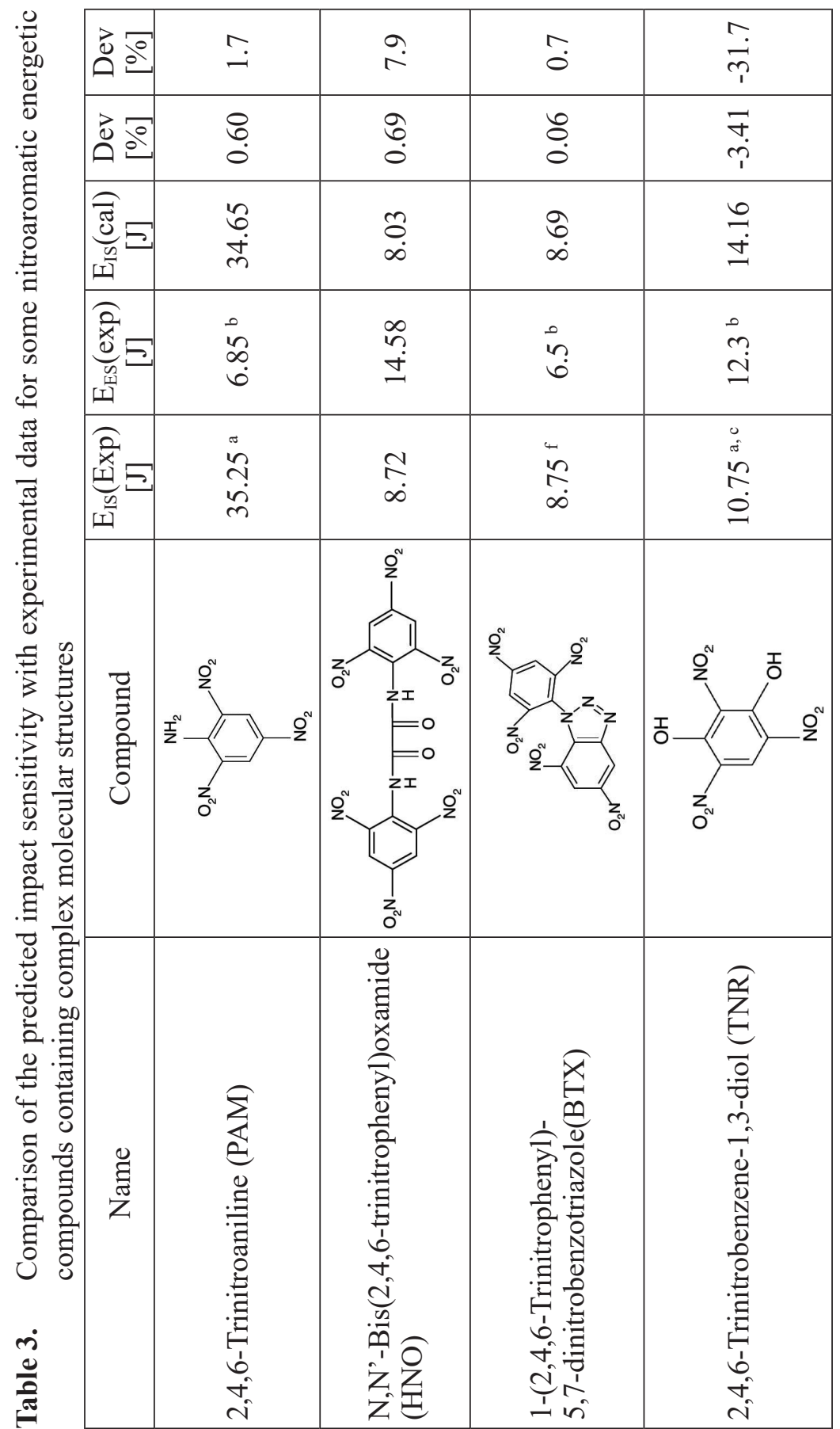




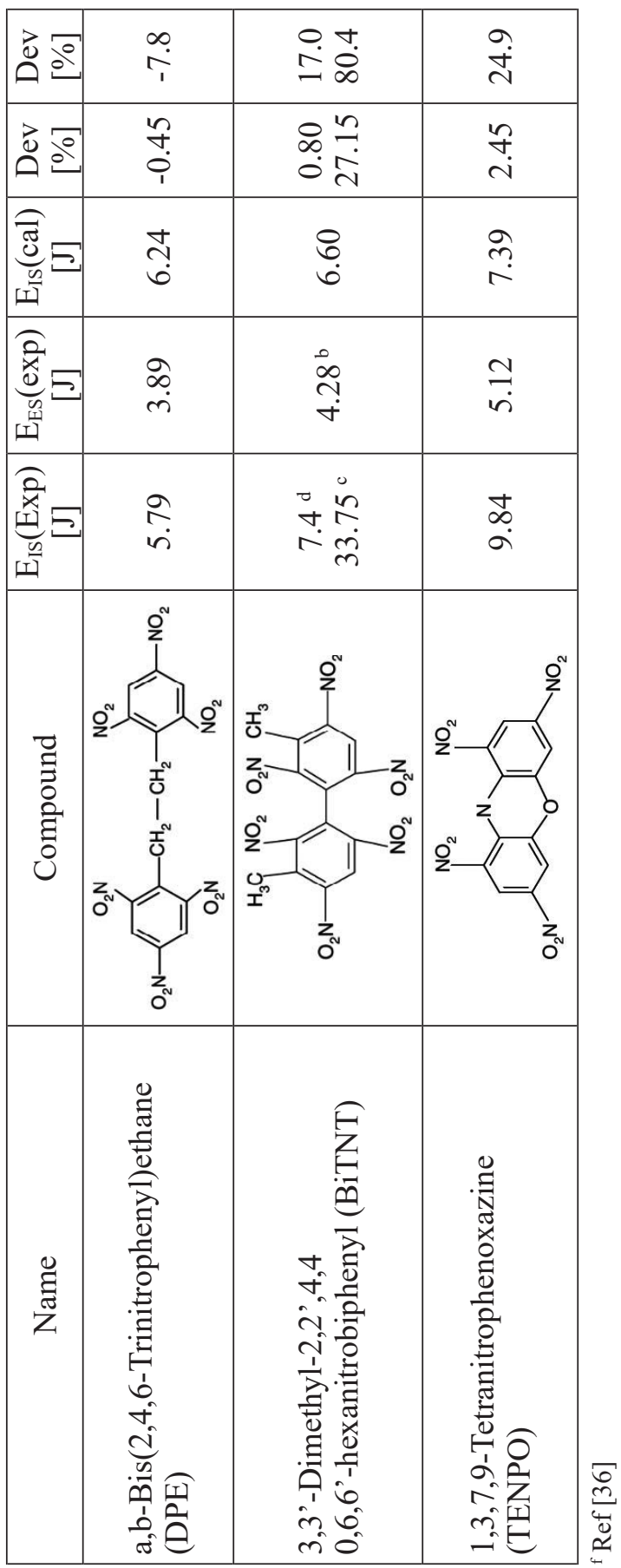




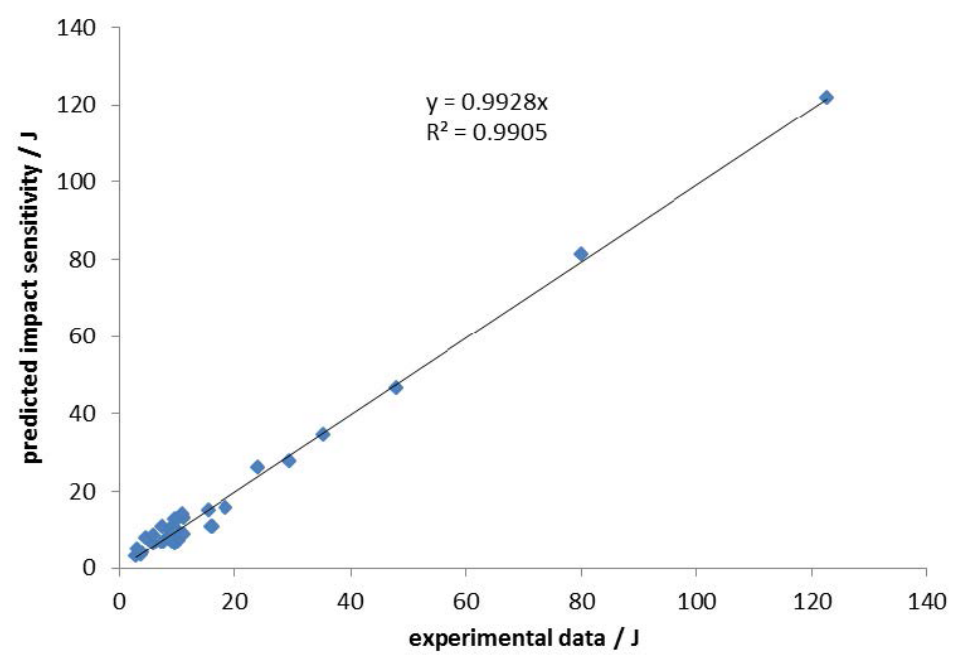

Figure 1. The relationship between predicted impact sensitivity values and experimental data of nitroaromatic which were presented in Tables 1 and 3.

Table 2. Statistical parameters for variables in Equation 1

\begin{tabular}{|c|c|c|c|c|c|}
\hline Variable & Coefficient & $\begin{array}{c}\text { Standard } \\
\text { error }\end{array}$ & P-value & $\begin{array}{c}\text { Lower bound } \\
(95 \%)\end{array}$ & $\begin{array}{c}\text { Upper bound } \\
(95 \%)\end{array}$ \\
\hline Intercept & 2.572 & 0.8961 & 0.0075 & 0.7389 & 4.4044 \\
\hline$E_{E S}$ & 0.942 & 0.1030 & 0.0000 & 0.7312 & 1.1524 \\
\hline$F_{n-N H 2}$ & 34.175 & 0.7720 & 0.0000 & 32.5960 & 35.7537 \\
\hline$F_{I S}^{+}$ & 17.105 & 1.5888 & 0.0000 & 13.8551 & 20.3541 \\
\hline$F_{I S}$ & -8.272 & 1.5544 & 0.0000 & -11.4511 & -5.0931 \\
\hline
\end{tabular}

\section{Conclusions}

In this article it was shown that there is a reliable correlation between the impact sensitivity of nitroaromatic energetic compounds and their electric spark sensitivity measured using an RDAD instrument. In the new proposed relationship, the impact sensitivity is found to be a function of the electrostatic sensitivity, the number of $\mathrm{NH}_{2}$ groups substituted into the 2,4,6-trinitrophenyl ring, and the non-additive structural parameters, $F_{I S}^{+}$and $F_{I S}^{-}$. The novel proposed correlation can predict the $E_{I S}$ of a nitroaromatic energetic compound with general formula $\mathrm{C}_{\mathrm{a}} \mathrm{H}_{\mathrm{b}} \mathrm{N}_{c} \mathrm{O}_{\mathrm{d}}$. Also the present method can help to elucidate the 
mechanism of initiation of energetic materials by impact and electric spark sensitivity. Moreover, this new relationship can be used to design novel ideal energetic materials.

\section{References}

[1] Sikder A.K., Maddala G., Agrawal J.P., Singh H. Important Aspects of Behaviour of Organic Energetic Compounds: A Review, J. Hazard. Mater. A, 2001, 84, 1-26.

[2] Zeman S., New Aspects of Initiation Reactivities of Energetic Materials Demonstrated on Nitramines, J. Hazard. Mater. A, 2006, 132, 155-164.

[3] Keshavarz M.H., Jaafari M., Investigation of the Various Structure Parameters for Predicting Impact Sensitivity of Energetic Molecules via Artificial Neural Network, Propellants Explos. Pyrotech., 2006, 31, 216-225.

[4] Keshavarz M.H., Motamedoshariati H., Pouretedal H.R., Kavosh Tehrani M., Semnani A., Prediction of Shock Sensitivity of Explosives Based on Small Scale Gap Test, J. Hazard. Mater. A, 2007, 145, 109-112.

[5] Keshavarz M.H., Pouretedal H.R., Semnani A., Simple Way to Predict Electrostatic Sensitivity of Nitroaromatic Compounds, Chemistry, 2008, 17, 470-484.

[6] Keshavarz M.H., Theoretical Prediction of Electric Spark Sensitivity of Nitroaromatic Energetic Compounds based on Molecular Structure, J. Hazard. Mater., 2008, 153, 201-206.

[7] Zeman S., Kočí J., Electric Spark Sensitivity of Polynitro Compounds. Part IV: A Relation to Thermal Decomposition Parameters, HanNeng CaiLiao, 2000, 8, $18-26$.

[8] Zeman V., Kočí J., Zeman S., Electric Spark Sensitivity of Polynitro Compounds. Part II: A Correlation with Detonation Velocity of Some Polynitro Arenes, HanNeng CaiLiao, 1999, 7, 127-32.

[9] Zeman S., A Study of Chemical Micromechanism of the Organic Polynitro Compounds Initiation, Ch. 2, in: Energetic Materials, (Politzer P., Murray J., Eds.), Part II, Elsevier, Amsterdam, 2003, p. 25; ISBN 0444515194.

[10] Roux M., Auzanneau M., Brass C., Electric Spark and ESD Sensitivity of Reactive Solids. Part I: Experimental Results and Reflection Factors for Sensitivity Test Optimization, Propellants Explos. Pyrotech., 1993, 18, 317.

[11] Auzenau M., Roux M., Electric Spark and ESD Sensitivity of Reactive Solids. Part II: Energy Transfer Mechanism and Comprehensive Study on E50, Propellants Explos. Pyrotech., 1995, 20, 96-101.

[12] Hosoya F., Shiino K., Itabashi K., Electric Spark Sensitivity of Heat Resistant Polynitroaromatic Compounds, Propellants Explos. Pyrotech., 1991, 16, 119-22.

[13] Skinner D., Olson D., Block-Bolten A., Electrostatic Discharge Ignition of Energetic Materials, Propellants Explos. Pyrotech., 1997, 23, 34-42.

[14] Zeman S., Kočí J., Electric Spark Sensitivity of Polynitro Compounds: Part IV. A 
Relation to Thermal Decomposition Parameters, HanNeng CaiLiao, 2000, 8, 18.

[15] Kočí J., Zeman V., Zeman S., Electric Spark Sensitivity of Polynitro Compounds: Part V: A Relationship between Electric Spark and Impact Sensitivities of Energetic Material, Energ. Mater., 2001, 9, 60-65.

[16] Zeman S., Valenta P., Zeman V., Electric Spark Sensitivity of Polynitro Compounds: A Comparison of some Authors Results, HanNeng CaiLiao, 1998, 6, 118.

[17] Zeman S., Pelikán V., Majzlík J., Electric Spark Sensitivity of Nitramines. Part I. Aspects of Molecular Structure, Cent. Eur. J. Energ. Mater., 2006, 3(3), 27-44.

[18] Agraval G.P., High Energy Materials, Propellants, Explosives and Pyrotechnics, Wiley-VCH, 2010, Ch. 3; ISBN 978-3-527-32610-5.

[19] Jun Z., Xin-lu C., Bi H., Xiang-dong Y., Neural Networks Study on the Correlation Between Impact Sensitivity and Molecular Structures for Nitramine Explosives, Struct. Chem., 2006, 17, 501-507.

[20] Lai W-P, Lian P., Wang B-Z., Ge Z-X., New Correlations for Predicting Impact Sensitivities of Nitro Energetic Compounds, J. Energ. Mater., 2010, 28, 45-76.

[21] Song X., Cheng X., Yang X., Bi H., Relationship between the Bond Dissociation Energies and Impact Sensitivities of some Nitroexplosives, Propellants Explos. Pyrotech., 2006, 31, 306-10.

[22] Murray J., Concha M., Politzer P., Links between Surface Electrostatic Potentials of Energetic Molecules, Impact Sensitivities and $\mathrm{C}-\mathrm{NO}_{2} / \mathrm{N}-\mathrm{NO}_{2}$ Bond Dissociation Energies, Mol. Phys., 2009, 107, 89-97.

[23] Jungova M., Zeman S., Husarova A., Friction Sensitivity of Nitramines. Part I: Comparison with Impact Sensitivity and Heat of Fusion, HanNeng CaiLiao, 2011, 6, 603-606.

[24] Mullay J., Relationships between Impact Sensitivity and Molecular Electronic Structure, Propellants Explos. Pyrotech., 1987, 12, 121-124.

[25] Mullay J.A., Relationship between Impact Sensitivity and Molecular Electronegativity, Propellants Explos. Pyrotech., 1987, 12, 60-63.

[26] Zohari N., Keshavarz M.H., Seyedsadjadi S.A., A Link between Impact Sensitivity of Energetic Compounds and their Activation Energies of Thermal Decomposition, J. Thermal Anal. Calorim., 2014, 117, 423-432.

[27] Zeman S., Krupka M., New Aspects of Impact Reactivity of Polynitro Compounds. Part II: Impact Sensitivity as “The First Reaction” of Polynitro Arenes, Propellants Explos. Pyrotech., 2003, 28, 249-255.

[28] Zohari N., Keshavarz M.H., Seyedsadjadi S.A., The Advantages and Shortcomings of Using Nano-sized Energetic Materials, Cent. Eur. J. Energ. Mater., 2013, 10(1), 135-147.

[29] Palm W.J. III, Introduction to Matlab for Engineers, McGraw-Hil, New York, 2005, ISBN 978-0-07-353487-9.

[30] Keshavarz M.H., Zohari N., Seyedsadjadi S.A., Validation of Improved Simple Method for Prediction of Activation Energy of the Thermal Decomposition of Energetic Compounds, J. Therm. Anal. Calorim., 2013, 114, 497-510.

[31] Dobratz B.M., The Insensitive High Explosive Triaminotrinitrobenzene (TATB): 
Development and Characterization - 1888 to 1994, LA-13024H.UC-741 Los Alamos: Los Alamos Scientific Laboratory, 1995.

[32] Rice B.M., Hare J.J., A Quantum Mechanical Investigation of the Relation between Impact Sensitivity and the Charge Distribution in Energetic Molecules, J. Phys. Chem. A, 2002, 106, 1770.

[33] Storm C.B., Stine J.R., Kramer J.F., Chemistry and Physics of Energetic Materials, (Bulusu S.N., Ed.), Kluwer Academic Publishers, Dordrecht, The Netherlands, 1990, p. 605; ISBN 978-94-010-7413-1.

[34] Zeman S., New Aspects of Impact Reactivity of Polynitro Compounds. Part IV: Allocation of Polynitro Compounds on the Basis of their Impact Sensitivities, Propellants Explos. Pyrotech., 2003, 28, 308-13.

[35] Wang R., Jiang J., Pan Y., Cao H., Cui Y., Prediction of Impact Sensitivity of Nitro Energetic Compounds by Neural Network Based on Electrotopological-State Indices, J. Hazard. Mater., 2009, 166, 155-86.

[36] Gibbs T.R., Popolato A., Los Alamos Series on Dynamic Material Properties, University of California Press, 1980. 
